\title{
Inkjet printing and inkjet infiltration of functional coatings for SOFCs fabrication
}

\author{
Rumen I. Tomov ${ }^{1}$, Ryan Duncan ${ }^{1}$, Mariusz. Krauz ${ }^{2}$, R. Vasant Kumar ${ }^{1}$ and Bartek A. Glowacki ${ }^{1,3,4}$ \\ ${ }^{1}$ Department of Materials Science and Metallurgy, University of Cambridge, United Kingdom \\ ${ }^{2}$ Institute of Power Engineering - Ceramic Department CEREL, Poland \\ ${ }^{3}$ Bernal Institute, Department of Physics and Energy, University of Limerick, Plassey, Ireland \\ ${ }^{4}$ Institute of Power Engineering, Warsaw, Poland
}

\begin{abstract}
Inkjet printing fabrication and modification of electrodes and electrolytes of SOFCs were studied. Electromagnetic print-heads were utilized to reproducibly dispense droplets of inks at rates of several $\mathrm{kHz}$ on demand. Printing parameters including pressure, nozzle opening time and drop spreading were studied in order to optimize the inks jetting and delivery. Scanning electron microscopy revealed highly conformal $\sim 6-10 \mu \mathrm{m}$ thick dense electrolyte layers routinely produced on cermet and metal porous supports. Open circuit voltages ranging from 0.95 to $1.01 \mathrm{~V}$, and a maximum power density of $\sim 180 \mathrm{~mW} . \mathrm{cm}^{-2}$ were measured at $750{ }^{\circ} \mathrm{C}$ on Ni-8YSZ/YSZ/LSM single cell $50 \times 50 \mathrm{~mm}$ in size. The effect of anode and cathode microstructures on the electrochemical performance was investigated. Two - step fabrication of the electrodes using inkjet printing infiltration was implemented. In the first step the porous electrode scaffold was created printing suspension composite inks. During the second step inkjet printing infiltration was utilized for controllable loading of active elements and a formation of nano-grid decorations on the scaffolds radically reducing the activation polarization losses of both electrodes. Symmetrical cells of both types were characterized by impedance spectroscopy in order to reveal the relation between the microstructure and the electrochemical performance.
\end{abstract}

\section{Introduction}

Environmental and economic concerns regarding future use of fossil fuels for energy production have been driving forces behind considerably renewed interest in fuel cell technologies. Solid Oxide Fuel Cells (SOFCs) can facilitate a direct electrochemical conversion of the energy stored in the fuel into electricity and heat without the efficiency limitations inherent to heat engines governed by the Carnot cycle and without polluting emissions. SOFCs high electrical efficiencies $(\sim 60 \%)$ can substantially exceed those typical for coal-fired power plants ( 35\%). Fuel cells can be scaled across a wide range of sizes - from micro-systems with outputs as small as few $\mathrm{W}$ to facilities operating in MW range. Depending on the design, SOFCs can operate at different temperatures within the region of $500-1000^{\circ} \mathrm{C}[1,2]$. The state-of-theart commercial SOFCs are based on a combination of cermet anodes (e.g. Ni/YSZ), ion-conducting ceramic electrolyte materials (yttria-stabilized zirconia (e.g. 8YSZ)) and perovskite-based composite cathodes (e.g. $\mathrm{La}_{1-\mathrm{x}} \mathrm{Sr}_{\mathrm{x}} \mathrm{MnO}_{3-8} / 8 \mathrm{YSZ}$ ). The above combination offers chemical and thermal stability in oxidizing and reducing atmospheres and good ionic conductivity over a wide range of conditions [3, 4]. Ni-YSZ anodes are preferred due to the exemplary catalytical properties of $\mathrm{Ni}$ for hydrogen oxidation as well as their sufficient electrical conductivity, mechanical strength and good compatibility [5]. However operating SOFCs at temperatures of $800-1000^{\circ} \mathrm{C}$ leads to some limitations in their design and operation - e.g. necessity for utilization of expensive corrosive-resistant interconnects - and can be detrimental to the durability of the cell causing $\mathrm{Ni}$ catalyst degradation through coarsening and poisoning. Currently a shift towards intermediate temperatures $\left(<800^{\circ} \mathrm{C}\right)$ is considered essential for lowering the production and operational costs of SOFCs. The advantages of a reduced-temperature operation include better system compactness and wider materials choice (e.g. stainless steel porous supports providing good electrical conduction, high mechanical strength, favourable thermal distribution due to the high thermal conduction and rapid start-up times) [6]. Lowering the working temperature however results in reduction of the overall electrochemical performance due to increased Ohmic losses and electrodes' polarization losses both related to thermally activated reactions. There are several development strategies for intermediate temperature SOFC. One of them is based on lowering the Ohmic resistance by implementing thinner electrolyte and substituting $8 \mathrm{YSZ}$ with higher electronic conductivity material like doped ceria $\left(\mathrm{Gd}: \mathrm{CeO}_{2}-(\mathrm{GDC})\right)$. The other is perusing increase cathodes and anodes catalytic activities through nano-engineering of the porous electrodes' surfaces. The performance of the state-of-the- 
art commercial cathodes based on $\mathrm{La}_{1-\mathrm{x}} \mathrm{Sr}_{\mathrm{x}} \mathrm{MnO}_{3-\delta}$ (LSM) is hindered by insufficient oxygen reduction reaction (ORR) activity and low oxygen ion conductivity at intermediate working temperatures. In recent years a significant progress has been made towards reducing the polarization losses and enhancing electrochemical activity via infiltration of active precursors into the electrode scaffolds [7-10]. Transitional metal oxide infiltration of LSM based cathodes is expected to increase substantially the density of ORR sites and lower the polarization related losses.

This study reports on the application of Inkjet Printing technique (IJP) for the fabrication and manipulation of SOFC components - thin electrolytes and engineered porous electrodes. The advantages of IJP were implemented in realization of different strategies for the optimisation of intermediate temperature SOFCs performance - fabrication of thin electrolytes, compositional variations of the anodes and infiltration of porous composite cathode scaffolds. The IJP is simple and cost-effective non-contact "wet" technique for fabrication of patterns and coatings onto variety of surfaces. It allows utilization of very thin fragile porous support (ceramic or metal) and is insensitive to a certain degree of substrate surface irregularity. IJP can reproducibly dispense droplets in the range of pico to nano-L volumes at high rates $(\mathrm{kHz})$. Drop-on-demand $(D o D)$ inkjet printing offers excellent thickness and uniformity control and introduces the possibility of printing $2 \mathrm{D}$ and $3 \mathrm{D}$ patterns. Inkjet systems have wide scale of application - from experimentation platforms working with customized inks to mass manufacturing systems that can print rapidly and competitively on industrial scale. The technology is cost effective and environmentally friendly through waste minimization of expensive precursors. The influence of the major printing parameters and the required optimization steps were explored for both suspension and solution inks. The production of anodes and electrolyte coatings with a modified Domino print head was reported previously by Tomov et al. [9, 10] using suspension inks. Wang et al. [11] deposited GDC electrolytes on NiO-8YSZ cermet anodes using sol-gel-based solutions. Sukeshini et al. [12] employed a DMP-2831 printer for the deposition of 8 YSZ electrolyte layers and LSM-YSZ and LSM cathode layers onto $\mathrm{NiO}-8 \mathrm{YSZ}$ supports, reporting maximum power density of $450 \mathrm{~mW} / \mathrm{cm}^{2}$ at $850^{\circ} \mathrm{C}$ in hydrogen.

\section{Experimental}

\subsection{Inks preparation}

Electrolyte and electrode depositions as well as catalytic precursor (Co-) infiltrations were performed by an electromagnetically(EM) driven print head with 100 $\mu \mathrm{m}$ ruby nozzle orifice and X-Y planar positioning system. EM technology was chosen because it offers simplicity and reliability of use, as well as wider range of ink/suspension compatibility. The preparation of stable suspension and sol-gel inks is of critical importance for achieving repeatable jetting without clogging the nozzles. For the suspension inks commercial NiO, 8 YSZ and GDC powders were mixed with alpha-Terpineol and binders, and ball milled with 3 YSZ beads in 3YSZ bowls in a planetary mill. The mass load of the ceramic powders was limited by the rheological working window of the nozzles, which defined the regime of stable repeatable jetting. Hence the viscosity of the suspension inks had to be adjusted levels by adding lower viscosity solvents - Methanol $(\mathrm{MeOH})$ or 1-Propanol (PrOH). The cobalt precursor solution ink $(0.75 \mathrm{M}$ total metal concentration) was prepared by dissolving $\mathrm{Co}\left(\mathrm{NO}_{3}\right)_{2} \times 6 \mathrm{H}_{2} \mathrm{O}$ in $\mathrm{EtOH}$ and adding citric acid as a complexing agent. Jetting of all types of inks was optimized by drop visualization procedure with the aim to produce no satellite drops at practical Weber and Reynolds numbers. The inks were filtered through $3 \mu \mathrm{m}$ glass micro-fibre filters before being loaded into the nozzle compartments. The nozzles were observed to execute reproducible drop on demand tasks without clogging the internal fluidic pathways of the assembly.

\subsection{Cells fabrications}

Anode supported cells $(50 \times 50 \mathrm{~mm})$ were fabricated by printing electrolyte suspension ink onto pre-fired tapecasted $\mathrm{NiO}-3 \mathrm{YSZ}$ anodes. After sintering at $1400{ }^{\circ} \mathrm{C} \mathrm{LSM}$ cathodes were screen printing and fired at $1150{ }^{\circ} \mathrm{C}$. Uniform electrolyte printing procedures involved repeated printing of hexagonal lattices with different lattice constants at optimized jetting parameters.

Anode symmetrical cells were fabricated by printing a $10 \mathrm{~mm}$ x $10 \mathrm{~mm}$ squares of NiO-8YSZ-GDC composite inks (prepared in different 8YSZ:GDC ratios) on each side of commercial circular dense YSZ substrates with a diameter of $20 \mathrm{~mm}$ and thickness of $200 \mu \mathrm{m}$. After sintering at $1150{ }^{\circ} \mathrm{C}$ in air samples were reduced and tested under an atmosphere of $\mathrm{Ar} / 4 \% \mathrm{H}_{2}$ at a flow rate of $150 \mathrm{~mL} / \mathrm{min}$. Cathode symmetrical cells were fabricated by inkjet printing of LSM/GDC composite cathodes on each side of circular dense 8YSZ substrates and sintering at $1100{ }^{\circ} \mathrm{C}$ in air for 2 hours. The $\mathrm{Co}\left(\mathrm{NO}_{3}\right)_{2}$ inkjet printing infiltrations were performed at variable substrate temperature $\left(20\right.$ to $\left.40{ }^{\circ} \mathrm{C}\right)$ in order to investigate the influence of the viscosity variation of the ink on the Co-oxide distribution. Each drop $(\sim 40 \mathrm{~nL}$ as, determined by drop visualisation) contained $0.69 \mu \mathrm{g}$ of $\mathrm{Co}\left(\mathrm{NO}_{3}\right)_{2} \times 6 \mathrm{H}_{2} \mathrm{O}$ and each layer of infiltration(resulting from the infiltration of 64 drops) contained $24 \mu \mathrm{g}$ of $\mathrm{Co}_{3} \mathrm{O}_{4}$ nanoparticles.

\subsection{Characterization}

Electrochemical impedance spectra (EIS) of the symmetrical cells were measured with the electrochemical interface and a frequency response analyzer (Solartron 1260) under the open-circuit voltage (OCV) condition. Symmetrical cells featuring each of the three anode compositions (Ni/8YSZ, Ni/GDC, Ni/25:75 GDC:8YSZ) as well as Co-modified LSM/GDC cathode symmetrical cells were heated at $10{ }^{\circ} \mathrm{C} / \mathrm{min}$ ramping rate to temperatures from 600 to $800{ }^{\circ} \mathrm{C}$, and tested under $\mathrm{Ar} / 4 \% \mathrm{H}_{2}$ or ambient air in a frequency range of $1 \mathrm{MHz}$ to $10 \mathrm{mHz}$ with $\mathrm{AC}$ amplitude of $10 \mathrm{mV}$. The Nyquist plots were constructed and fitted to the semicircles by employing least squares analysis and the NewtonRaphson method via Excel Solver. Silver mesh 
was painted to the electrodes in order to ensure conductivity along the surface of the electrodes. I-V characteristics of the fuel cells were tested in a specially developed ceramic enclosure equipped with gold current collectors. The tests were performed at 700 , 750 and $800^{\circ} \mathrm{C}$ using humidified hydrogen as the fuel (at a constant flow rate of $200 \mathrm{ml} / \mathrm{min}$ ) and ambient air as the oxidant.

\section{Results and discussions}

The successful application of IJP required three different stages of optimization:

- Inks optimization

- Jetting optimization

- Drops spreading optimization

\subsection{Inks optimization}

Particle size distributions analyses of the suspension inks produced via ball milling showed typically multi-modal particles distributions. Figure 1 presents the distribution of $\mathrm{NiO}$ and GDC inks milled for various time durations. The inks milled for 4 hours showed substantial broad tail. Extending the milling time to 10 hours led to sharper biand tri modal distributions with $\mathrm{d}(0.5)=0.129 \mu \mathrm{m}$ for GDC ink and $\mathrm{d}(0.5)=0.443 \mu \mathrm{m}$ for NiO. Similar procedure was used for 8 YSZ and LSM inks. Using $3 \mu \mathrm{m}$ glass fibre filter during the loading of inks into the nozzle chamber ensured stable jetting operation without clogging events and without retention of any significant ink fraction.

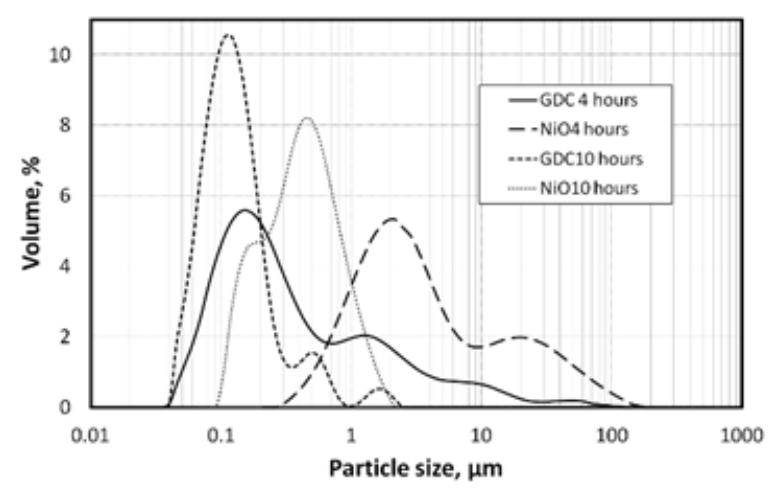

Figure 1. Particle size distribution of GDC and $\mathrm{NiO}$ ink diluted with methanol.

The viscosity of two separate $\mathrm{NiO}$ and GDC inks as well as NiO-GDC composite inks prepared by dilution in methanol in proportion $1: 1$ by volume was measured with a rotational viscometer (see Figure 2). The value of the viscosity at $\gamma=30 \mathrm{~s}^{-1}$ was $0.0067 \mathrm{Pas}$ for GDC, $0.0072 \mathrm{Pas}$ for $\mathrm{NiO}$ and $0.0075 \mathrm{Pas}$ for $\mathrm{NiO}-G D C$ mixture. Mixing NiO and GDC into a single anode ink lead to an increase of viscosity due to a partial agglomeration during mixing procedure. The viscosity dynamics was found to follow similar behaviour for all suspension inks over the measured shear rate range. The viscosity of $0.75 \mathrm{M}$ sol $\mathrm{Co}\left(\mathrm{NO}_{3}\right)_{2}$ ink was tested at different temperatures and lower shear rates (see Figure 3 ). The viscosity range of 0.005 to $0.025 \mathrm{Pas}$ was established within 5 to $40^{\circ} \mathrm{C}$ temperature variation. The choice of the infiltration temperature was restricted by the empirical rheological nozzle limit of $0.010 \mathrm{~Pa}$ s.

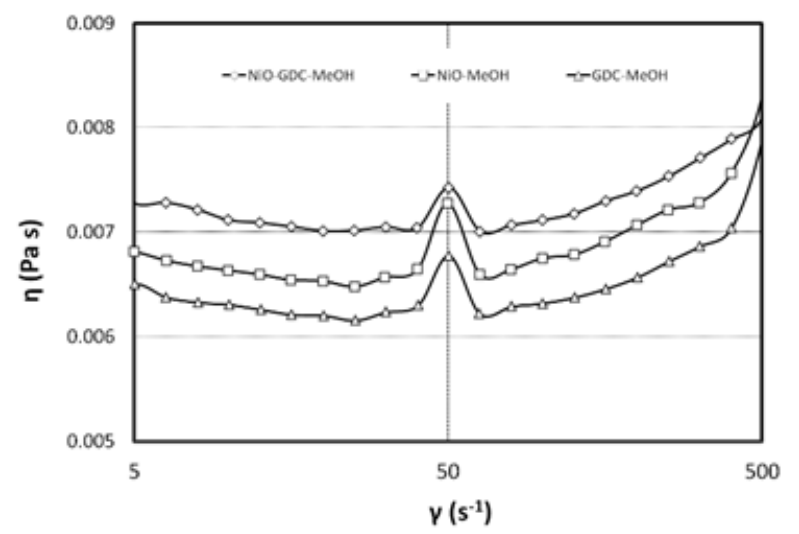

Figure 2. Dynamic viscosity measurement of $\mathrm{NiO}, \mathrm{GDC}$ and composite $\mathrm{NiO}-\mathrm{GDC}$ inks.

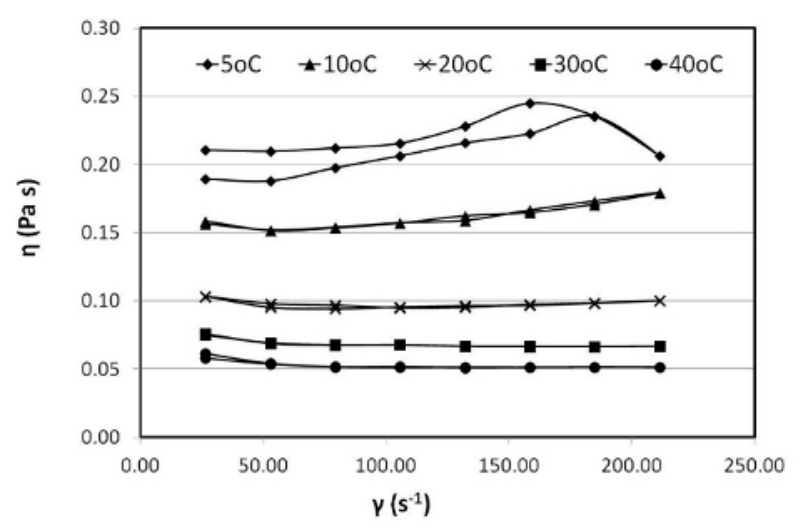

Figure 3. Dynamic viscosity measurement of $\mathrm{Co}\left(\mathrm{NO}_{3}\right)_{2}-\mathrm{EtOH}$ ink at different temperatures.

\subsection{Jetting optimization}

The tailored jetting should ideally result in a single drop formation without delayed satellite drops. This is essential for achieving desired thickness control of the coating. The use of drop visualisation system allowed rapid examination of the rheological suitability of all ink. Precise control of the drop volume, velocity and satellite drop formation was achieved by optimization of the printing parameters. Such optimisation for the electromagnetic print heads was based on the variation of carrier/solvent ratio, opening time and nozzle

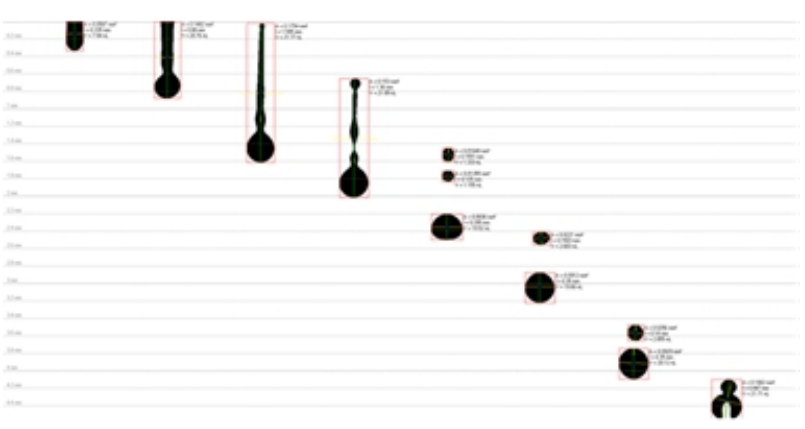

Figure 4. Drop visualisation jetting images of $10 \mathrm{wt} \% \mathrm{NiO}-$ GDC suspension ink under a pressure of 350 mbar and $250 \mu \mathrm{s}$ opening time. 
pressure. The initially released drop broke into a main drop and one or more smaller drops after it was detached from the nozzle. For optimised printing parameters the smaller drops soon merged with the main drop and formed back to a single drop ensuring that for suitable conditions no satellite drops would be deposited on the substrate. Figure 4 illustrates optimized drop formation behaviour of $10 \mathrm{wt} \% \mathrm{NiO}-\mathrm{GDC}$ suspension ink under a pressure of 350 mbar and $250 \mu$ s opening time.

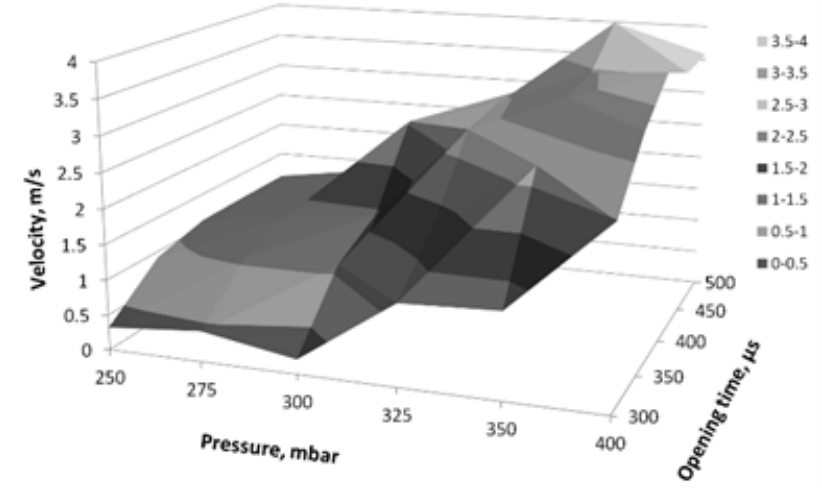

(a)

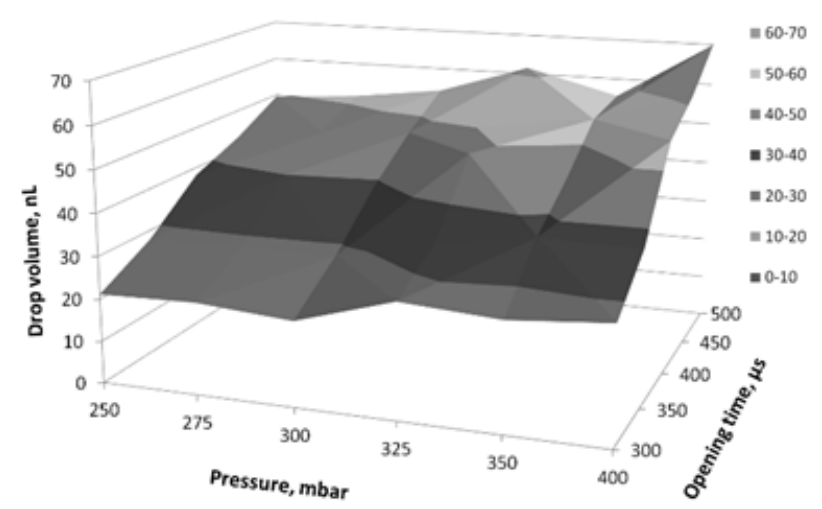

(b)

Figure 5. (a) Velocity data from the visualisation system showing jetting of $10 \mathrm{wt} \% \mathrm{NiO}-\mathrm{GDC}$ suspension ink; (b) Calculated drop volumes versus pressure (250-400 mbar) for tested opening times $(300-500 \mu \mathrm{s})$.

Figure 5 demonstrates the achievable range of drop volumes and velocities within the practical limits of opening times and pressures. It is clear that the drop volumes depended strongly on the opening time while the velocities were strongly influenced by the nozzle positive pressure.

\subsection{Spreading optimization}

The optimised velocities and drop volumes presented a problem for the deposition of thin coatings on supports with substantial porosity and wider pore size distribution. The standard printing procedure resulted in a penetration of the ink within the scaffold making deposition of free standing coating impossible. This issue was resolved by implementing inkjet printing on heated supports. The elevated temperature of the substrate surface led to a partial evaporation of the solvent effectively increasing the viscosity and the surface tension of the landing drops. The retention of the ink onto the porous surface allowed for building of free-standing membranes. On the other hand depositions at elevated temperatures can cause an immediate evaporation of the solvent at the periphery of the drop relic where the thickness of the deposit is relatively thin, effecting a net flux of ink radially outward resulting in so called "coffee ring effect". Such mechanism is detrimental, in that a film composed of multiple drop relics will be nonuniform in thickness.

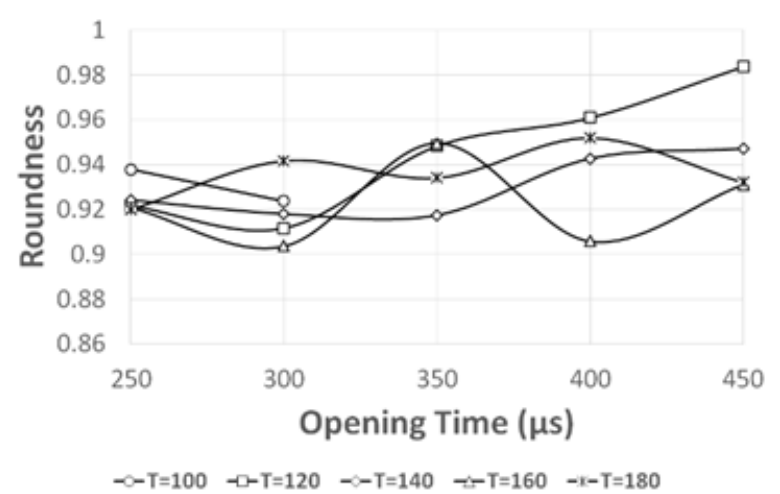

(a)

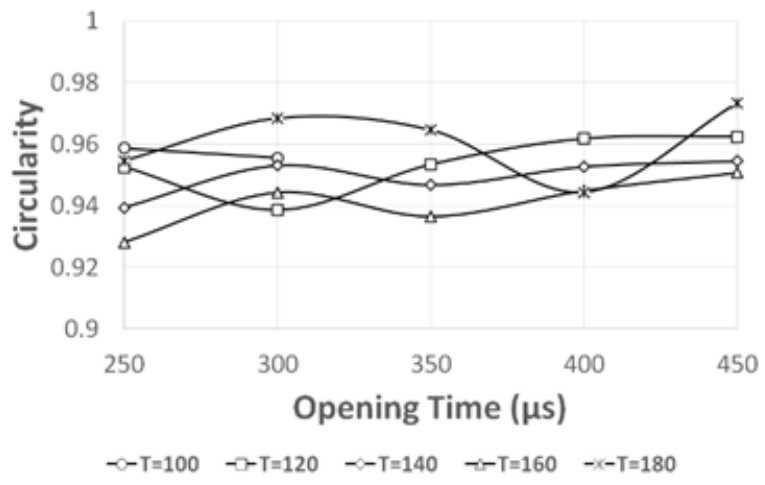

(b)

Figure 6. (a) Circularity and (b) roundness of the printed relics vs. opening times.

The problem was counteracted by the implementation of high vapour pressure solvent as ink carrier (alphaTerpineol). The evaporation of such solvent at the contact line created a surface tension gradient increasing towards the cooler drop centre and inducing a balancing Marangoni flow. An optimization of drops formation and spreading for the composite $\mathrm{NiO}-\mathrm{GDC}-\mathrm{MeOH}$ ink was performed for the pressure of $350 \mathrm{mbar}$ and opening time (OT) range of $250-450 \mu \mathrm{s}$ and substrate temperature (T) range $100-180^{\circ} \mathrm{C}$. Rasters of single drops were printed on heated dense 8YSZ electrolyte substrates and the geometric features of the drops were analyzed with ImageJ software. The values of interest were diameters, circularities $\left(\mathrm{C}=4 \pi A / p^{2}\right)$, and degrees of roundness $\left(\mathrm{R}=4 A / \pi a^{2}\right)$ where $\boldsymbol{A}$ was droplet area, $\boldsymbol{p}$ was droplet perimeter, and $\boldsymbol{a}$ was the major axis of an ellipse fit to the drop relic. Circularity and roundness varied over 0 to 1 , higher values being an indicator of a shape that is close in character to a perfect circle. Figure 6 (a) and (b) summarizes the image analysis data for drop relics formed at different substrate temperature. The visual representation of selected drop relics relevant to this optical analysis can be seen 
in Figure 7. The general preference for small relic diameter with high circularity and roundness numbers led to the choice of one sets of parameters resulting also in the desired absence of "coffee ring effect" - temperature of $120^{\circ} \mathrm{C}$, and opening time of $400 \mu \mathrm{s}$.

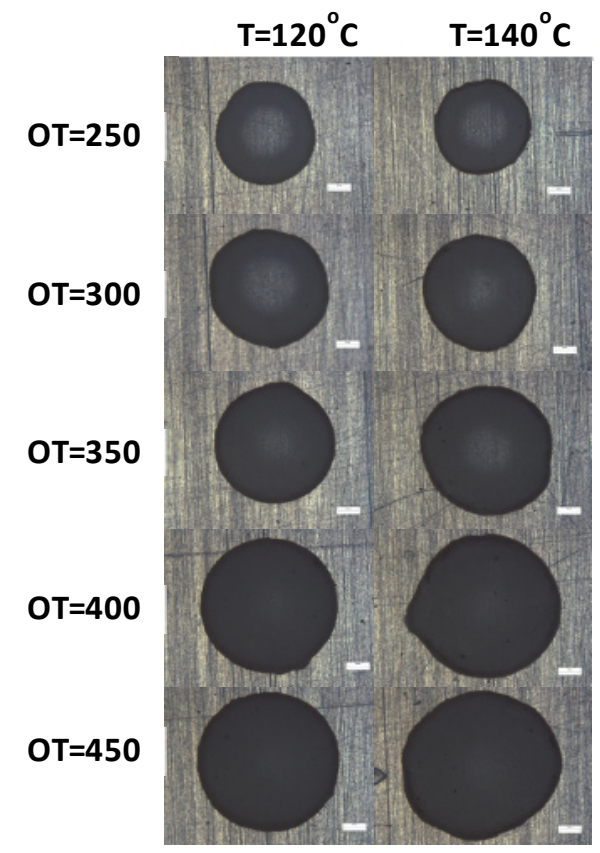

Figure 7. Images of a single drops relics for different opening times and substrate temperature. The white bar on all images represents $200 \mu \mathrm{m}$.

\subsection{Inkjet printing of thin electrolytes}

After choosing the optimum jetting and spreading parameters for $8 \mathrm{YSZ}$ inks, complete electrolyte coatings were printed on the $57 \mathrm{~mm} \times 57 \mathrm{~mm}$ square NiO-YSZ cermet supports using hexagonal arrays of droplets in reciprocating raster pattern. Figure 8 (a) and (b) shows SEM micrographs of the surface and the cross-section of 8 YSZ electrolyte membrane prepared by inkjet printing. 12 coatings of the $5 \mathrm{wt} \%$ suspension were printed and sintered at $1400 \mathrm{C}$. It is important to note that the resulting YSZ membrane, as thin as $\sim 5.7-5.9 \mu \mathrm{m}$, appeared to be highly dense and no open porosity was observed. The film had good interfacial cohesion with the support, without any cracks or delamination.

The I-V tests were performed at 700,750 and $800{ }^{\circ} \mathrm{C}$ using humidified hydrogen as the fuel (with different $\mathrm{H}_{2}: \mathrm{N}_{2}$ mixture ratios at constant flow rate of $200 \mathrm{ml} / \mathrm{min}$ ) and ambient air as the oxidant. The OCV value of $1.077 \mathrm{~V}$ measured at $800^{\circ} \mathrm{C}$ confirmed the gas-tightness of the membrane and was consistent with the cross-section appearance. The I-V tests showed maximum power densities of $\sim 220 \mathrm{~mW} / \mathrm{cm}^{2}$ for pure humidified hydrogen stream. Diluting the fuel with $\mathrm{N}_{2}$ as shown in the inset of Figure $8 \mathrm{~b}$ led to a substantial reduction of the maximum output power without change in the OCV values. The latter suggested the existence of concentration losses due to nonoptimized porous structure of the anode support.

Similar printing procedure was employed for deposition composite $\mathrm{GDC} / \mathrm{NiO}$ functional layer and GDC electrolyte coating on porous metal supports. Stainless steel porous supports were prepared by milling and pressing a mixture of 430L stainless steel powder and organic binder into circular pellets. As-prepared supports were sintered in a tube vacuum furnace at $1150{ }^{\circ} \mathrm{C}$ and cooled to room temperature at a ramp rate of $5{ }^{\circ} \mathrm{C} / \mathrm{min}$. Such sintering procedure gave sufficient mechanical strength to the supports for the subsequent handling. The density and the open porosity of the pellets were evaluated by Archimedes' method which revealed an open porosity of $\sim 40 \%$. The inspection of the SS430L supports sintered at $1150^{\circ} \mathrm{C}$ reveals small degree of surface waviness and relative mechanical fragility due to incomplete sintering. Hence the use of traditional ceramic coating techniques as screen printing was considered challenging. As IJP technique is insensitive to such degree of non-uniformity it was employed for the functional coatings development.

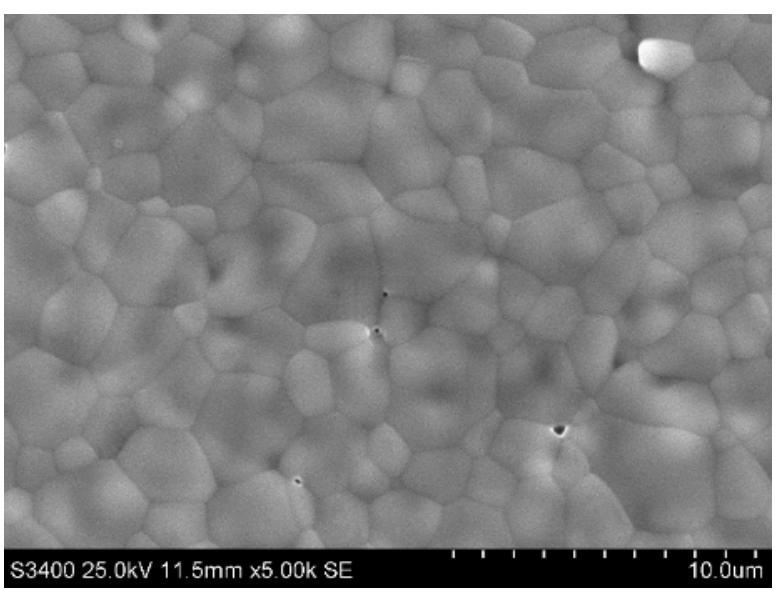

(a)

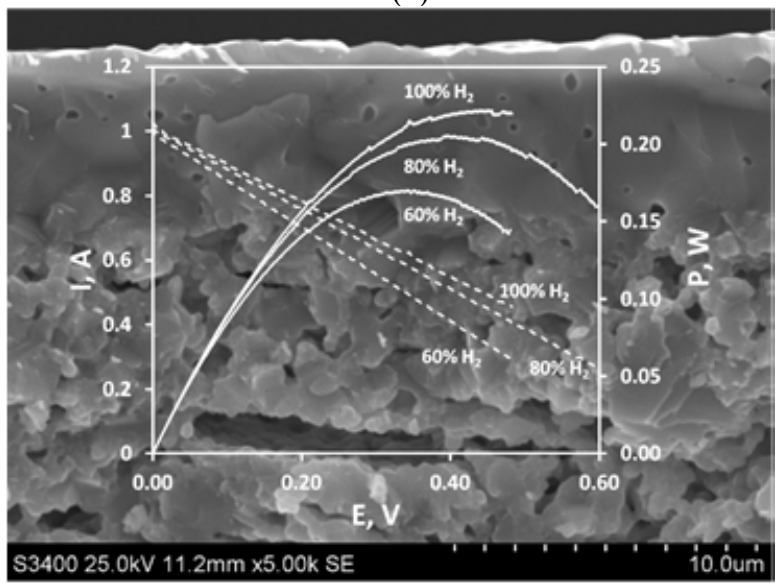

(b)

Figure 8. SEM micrographs of the (a) surface and (b) half-cell cross-section sintered at $1400{ }^{\circ} \mathrm{C}$. The inset shows the I-V results of the cell at $800^{\circ} \mathrm{C}$ and different fuel dilution levels.

Figure 9 represents cross sectional images of GDC/NiO-GDC/SS430L fractured half-cell fabricated with IJP under the optimized conditions. Electrolyte and anode coatings less than $15 \mu \mathrm{m}$ thick were deposited as free standing coatings. The sintering temperature of $1350^{\circ} \mathrm{C}$ was found sufficient for full densification of the electrolyte. The effect of surface non-uniformity planarization was evident. Some infiltration of the anode ink into the stainless steel support could be detected in the area adjacent to the anode-support interface (see the inset of Figure 9). 


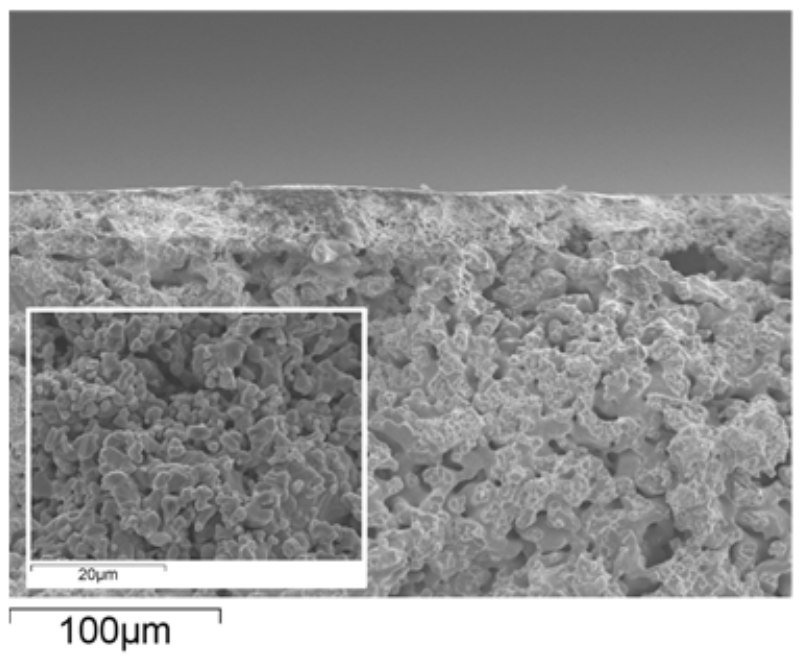

Figure 9. Cross sectional SEM image of GDC/Ni-GDC halfcell architecture inkjet printed on 430L stainless steel support and sintered in vacuum at $1350{ }^{\circ} \mathrm{C}$. The inset shows Ni-GDC ink residue infiltrated into an area adjacent to the anode interface.

\subsection{Anode symmetrical cells with variable composition}

The results of EIS studies of anode symmetrical cells tested with $\mathrm{Ar} / 4 \% \mathrm{H}_{2}$ can be seen in Figure 10a-c. The Nyquist plots obtained at different temperature exhibited suppressed semicircles with varying cross sectional points with $\mathrm{X}$ - axis at the low frequency end.

As expected, the polarization resistance $(R p)$ observed correlated with increasing the GDC content in the composite anode for temperatures above $700^{\circ} \mathrm{C}$ (see Figure $10 \mathrm{~d})$. The increase in temperature led to ASR values having weighted contribution from both ion conductive components (GDC and YSZ). This is consistent with GDC's having higher ionic conductivity than that of YSZ at these temperatures hence effectively promoting the charge transfer mechanism in the anode area.

On the other hand an increase of the polarization activation energy (Ea-p) proportional to the GDC composition was observed most likely related to the enhanced electronic conductivity of GDC at higher temperatures $($ Ea-p $=38.52,66.55$ and $83.58 \mathrm{~kJ} / \mathrm{mol}$ for YSZ, YSZ+GDC and GDC anodes respectively). Furthermore, as-measured Ohmic resistivity seems to be dominated by GDC component even at volume ratios of only $25 \mathrm{vol} \%$ while the activation energy (Ea-o) was found to be almost constant at different GDC levels.

\section{6 $\mathrm{Co}_{3} \mathrm{O}_{4}$ nano decorated LSM/GDC composite cathode}

The area-specific resistances (ASRs) of Co- infiltrated and non-infiltrated LSM/GDC cathode symmetric cells were measured at $600^{\circ} \mathrm{C}$ and $800^{\circ} \mathrm{C}$ (EIS data shown in Fig $11 \mathrm{a}$ and $\mathrm{b})$. The polarization resistance reduction due to $\mathrm{Co}_{3} \mathrm{O}_{4}$ nano-particles cathode surface decoration was more pronounced at lower temperatures.

A reduction of the activation polarization losses of almost one order of magnitude was observed as a direct result of Co-ink infiltration. The differences in the measured

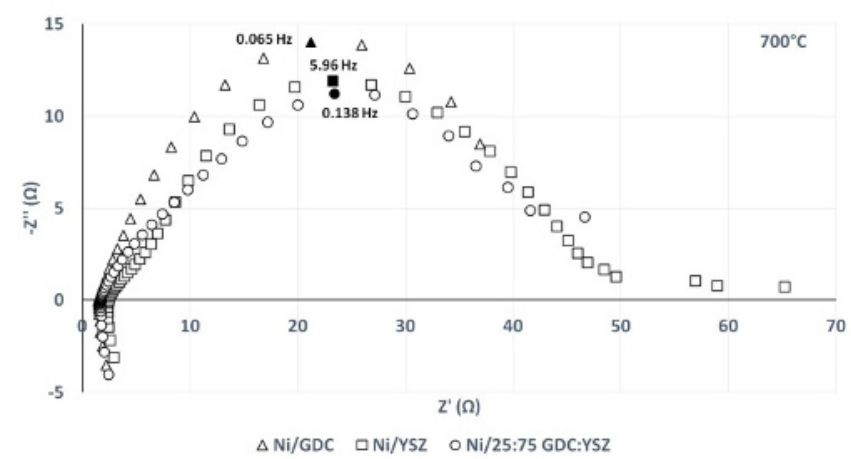

(a)

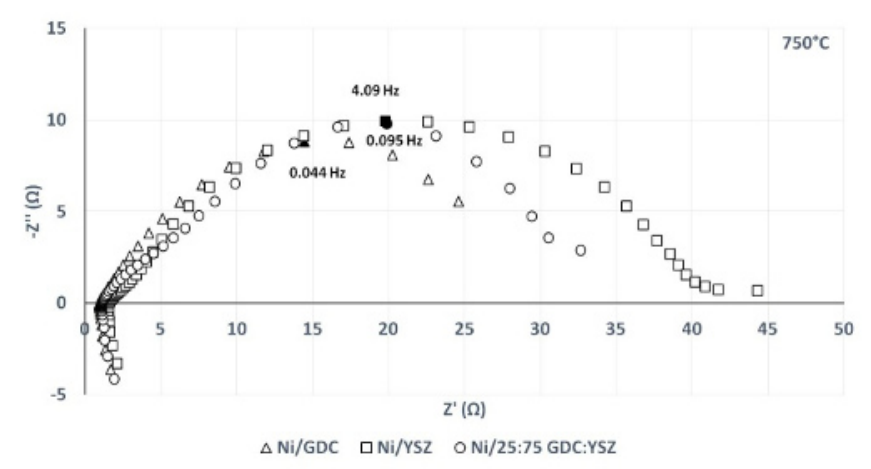

(b)

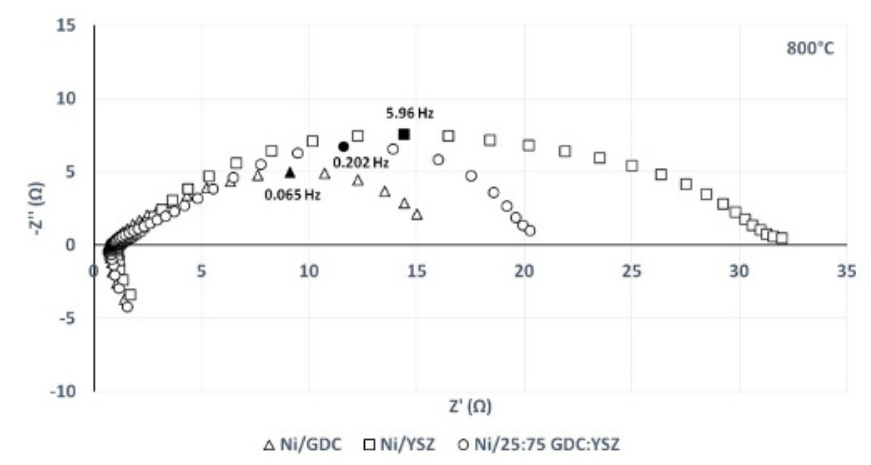

(c)

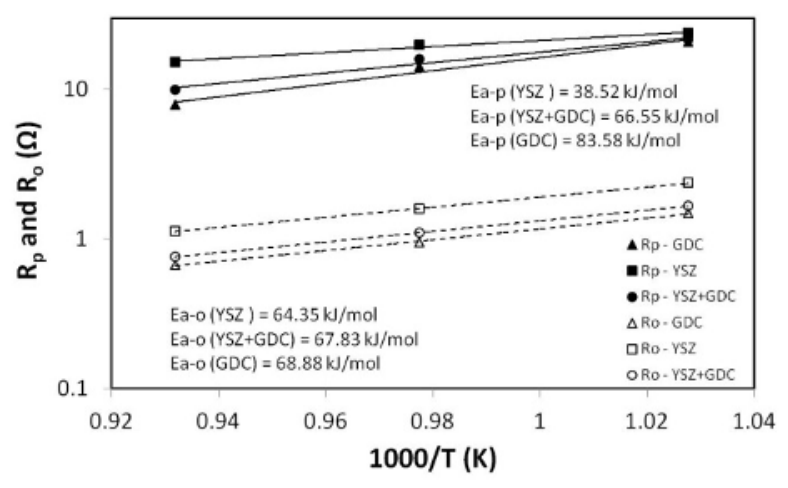

(d)

Figure 10. EIS data of symmetrical cells with anodes of various compositions measured in $\mathrm{Ar} / 4 \% \mathrm{H}_{2}$ at temperatures between 700 and $800^{\circ} \mathrm{C}$. 
ASR values suggested that at $600{ }^{\circ} \mathrm{C}$ the sample infiltrated at elevated temperature $\left(40^{\circ} \mathrm{C}\right)$ had lower polarization losses compared to the one infiltrated at room temperature. One could speculate that this was a result of a better coverage of the cathode scaffold with $\mathrm{Co}_{3} \mathrm{O}_{4}$ nanoparticles. Such effect was expected due to the lowered viscosity and improved wetting properties of the ethanol-based $\mathrm{Co}$ nitrate ink at higher temperatures. At $800^{\circ} \mathrm{C}$ the Nyquist plot revealed a second semicircle resolved at the low frequency end of the spectra for the sample infiltrated at $40^{\circ} \mathrm{C}$. This suggested the appearance of concentration losses associated with higher mass load of the infiltrate partially blocking the porous structure of the backbone (see Figure $11 \mathrm{~b}$ and Figure 12a). The size of $\mathrm{Co}_{3} \mathrm{O}_{4}$ nanoparticles was estimated to be between 100 and $200 \mathrm{~nm}$. EDS line scans as seen in Fig. 12b and 12c confirmed the superior more uniform depth distribution of $\mathrm{Co}$ in the case of the cathode infiltrated at elevated temperature.

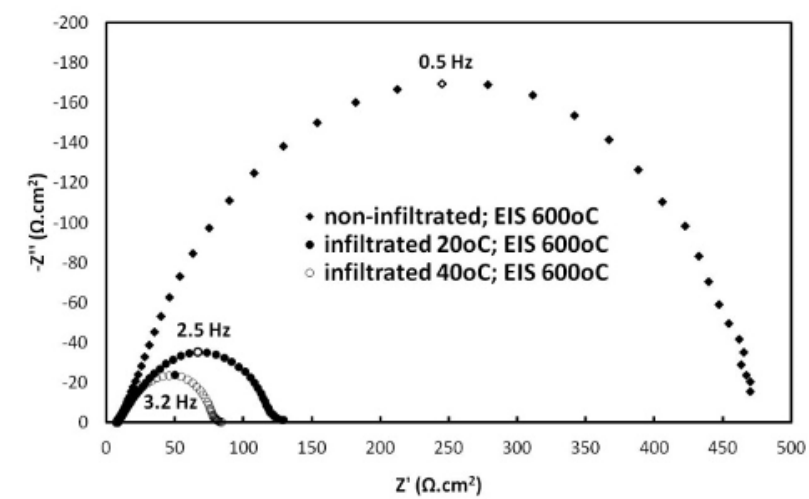

(a)

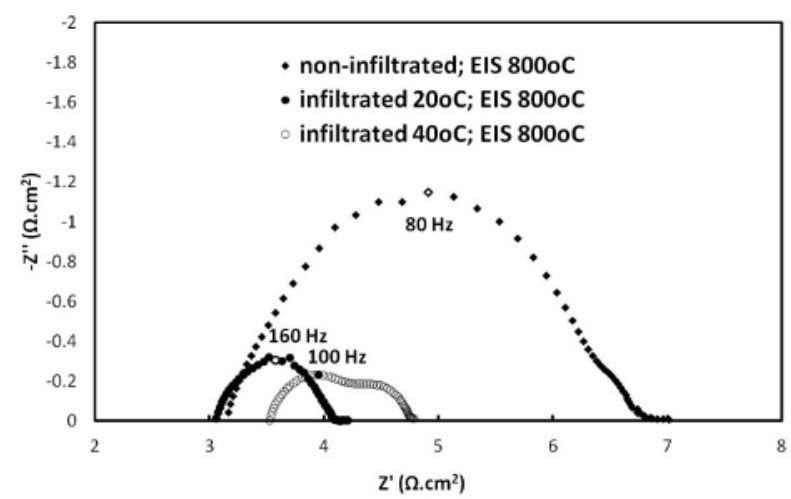

(b)

Figure 11. EIS spectra of LSM/GDC symmetrical cathode cells non-infiltrated and infiltrated at $20^{\circ} \mathrm{C}$ and $40{ }^{\circ} \mathrm{C}$ substrate temperatures. Data was measured for two different temperatures $-600{ }^{\circ} \mathrm{C}(\mathrm{a})$ and $800{ }^{\circ} \mathrm{C}(\mathrm{b})$.

\section{Conclusions}

The results of this study prove the feasibility of IJP technology for the fabrication and manipulation of SOFC functional coatings. The precision of jetting and ink delivery allowed us to print reproducibly 8YSZ free standing membranes as thin as $6 \mu \mathrm{m}$ onto porous uneven surfaces. Anodes optimization was demonstrated via compositional (YSZ:GDC) variation facilitated by the flexibility of composite ink mixing procedure in the inkjet printing processing. The employment of inkjet infiltration of Co nitrate ink into the LSM/GDC composite backbone produced $\mathrm{Co}_{3} \mathrm{O}_{4}$ nano-decoration of the cathode internal surface which led to substantial performance improvement achieved with precise control of the catalytic element depth distribution and minimum wastage of expensive precursors.

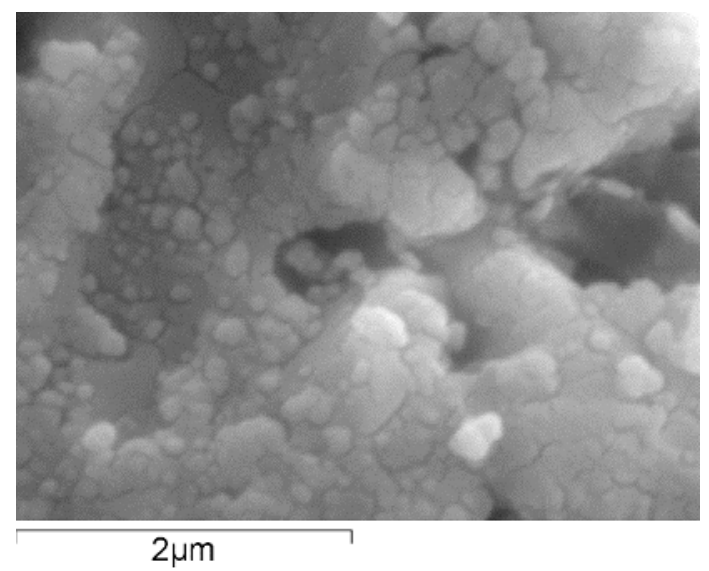

(a)

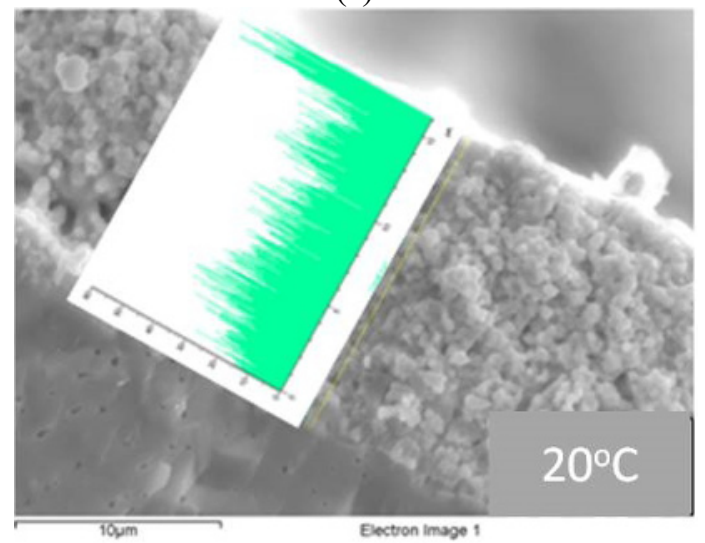

(b)

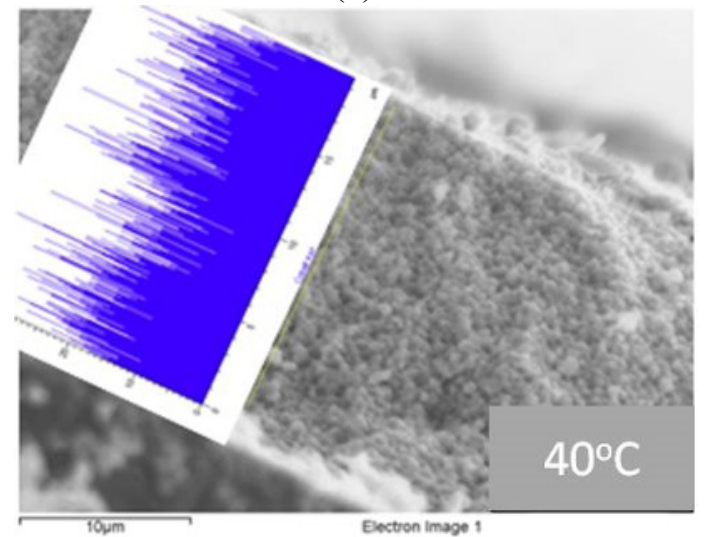

(c)

Figure 12. SEM cross-section micrograph (a) and EDS line scans of Co depth distribution for the samples infiltrated at $20^{\circ} \mathrm{C}$ (b) and $40^{\circ} \mathrm{C}(\mathrm{c})$.

\section{Acknowledgements}

The authors wish to acknowledge the EU 7th Framework Programme grant agreement 286100 (SENERES), as well as EPSRC grants - "Performance Optimisation of Intermediate Temperature - Solid Oxide Fuel Cells 
(IT - SOFCs) by Inkjet Printing on Porous Metal Substrates (JETCELL)" and "Tailoring of micro structural evolution in impregnated SOFC electrodes" for the financial support.

\section{References}

1. S. Singhal, Solid State Ionics 135 (1-4), 305-313 (2000)

2. Z.P. Shao, S.M Haile, J. Ahn, P.D. Ronney, Z.L. Zhan, S.A. Barnett, Nature 435, 795-798 (2005)

3. Weber, A., Ivers-Tiffee, E., Journal of Power Sources 127, 273-283 (2004)

4. I.R. Gibson, G.P. Dransfield, and J.T.S. Irvine, J. Eur. Ceram. Soc. 18, 661-667 (1998)

5. S.P. Jiang, S.H. Chan, S.H., J. Mater. Sci. 39, 44054439 (2004)

6. N.Q. Mihn, T. Takahashi, Science and Technologyof Ceramic Fuel Cells (Elsevier Ltd., Amsterdam 1995).

7. D. Ding, X. Li, S.Y. Lai, K. Gerdes and M. Liu, Energy Environ. Sci. 7, 552-575 (2014)

8. J.A. Kilner and M. Burriel, Annu. Rev. Mater. Res. 44, 365-393 (2014).

9. A. Atkinson, S. Barnett, R. J. Gorte, J. T. S. Irvine , A. J. McEvoy , M. Mogensen, S. C. Singhal, J. Vohs, Nature Materials 3, 17- 27 (2004)

10. S.C. Singhal and K. Kendall ed., High temperature solid oxide fuel cells: fundamentals, design and applications (Elsevier Ltd, Amsterdam 2003).

9. R.I. Tomov, M Krauz, J. Jewulski, S.C. Hopkins, J.R. Kluczowski, D.M. Glowacka, B.A. Glowacki, Journal of Power Sources 195, 7160-7167 (2010)

10. Ch. Wang, S.C. Hopkins, R.I. Tomov, R.V. Kumar, B.A. Glowacki, Journal of the European Ceramic Society 32, 2317-2324 (2012)

11. Ch. Wang, R.I. Tomov, R.V. Kumar, B.A. Glowacki, Journal of Materials Science 46, 6889-6896 (2011)

13. A.M. Sukeshini, R. Cummins, T.L. Reitz, R.M. Miller, J. Am. Ceram. Soc. 92 (12), 2913-2919 (2009) 